The following speech was given by Elizabeth McWeeny, President of the Canadian Council of Refugees, on the occasion of the opening of the tenth biennial conference of the International Association of the Study of Forced Migration, hosted by the Centre for Refugee Studies of York University in June 2006.

\title{
North-South Dialogues in Forced Migration
}

\author{
Elizabeth McWeeny
}

First let me express my thanks and appreciation to the International Association for Studies in Forced Migration for their collaboration with the Canadian Council for Refugees (CCR) in order to plan our conferences together. Yesterday, the CCR concluded its International Conference on Refugee Rights and we had an opportunity for participants to take advantage of both conferences. This collaboration between two sectors, the academics and researchers with the practitioners and advocates, demonstrates how close we are in interests that affect refugees. So I am here as a practitioner seeking dialogue, allies, and partnerships on the common themes on forced migration.

The theme of this conference, North-South Dialogues, provides us with several images:

- the global geographic flow of power and information mostly north to south and the flow of resources and cheaply produced goods south to north;

- the view of the north as powerful, developed, civilized, and privileged and the south as impoverished, underdeveloped or developing, enslaved, and exploited;

- the flow of displaced people from south to north and the factors flowing north to south causing these displacements.

While the imagery is simplistic and not always based on fact, the differences and imbalances they portray are very real indeed.

Recently I had cause to read again the actual text of the Universal Declaration of Human Rights. To what did our global community commit in 1948? The text is still very relevant and I challenge every signatory nation to do a self-audit on how we are living up to those inspiring words that promised so much.

\section{Building Alliances to Strengthen Advocacy}

The subtext for the CCR conference was "networking across borders." We used last weekend to discuss how NGOs can be more effective advocates with and for refugees when we work together. How do we ensure that refugee women's voices are heard and that they are included in the leadership of local and international efforts? Who are our partners? Who can we collaborate with on common interests and issues? What strategies can we develop collectively to give strength to each individual voice? Who will take leadership to bring us forward from here?

Oftentimes, NGOs find ourselves working in isolation or communicating with colleagues on a local, regional level but not internationally. This is something we must change. We know our governments talk to each other. They strategize, negotiate, and bargain away the rights of refugees for economic and political purposes. The standards for one country's policies on refugees are seen as the "best practice" by other states even though they are often the lowest common denominator and certainly not the good practices we want to see in place.

NGOs have the unique role to be the uncomfortable voice that questions, challenges, and urges our governments and the communities in which we live to change. If we are to be effective as the uncomfortable, challenging voice we have to be as successful as states at working together on an international level in order to intervene at the levels where decisions are really made.

As usual, we don't have the substantial resources of governments but in this age of technology we can certainly be far more collaborative than ten years ago. However, in considering potential allies I'd like to mention a few dynamics that are relevant to this gathering:

- Bridging NGOs with Common Focus

- Linkage between Human Rights Advocacy NGOs, Humanitarian Assistance, and Development NGOs

- NGO Reliance on Independent Research and the Academic Sector

- Voices of the South in the North

\section{Bridging NGOs with Common Focus}

The lines of communication are very thin between NGOs in countries that traditionally do not receive large numbers of 
asylum seekers and NGOs in those countries that host tens or hundreds of thousands of forced migrants. In planning the recent conference the CCR wanted to involve participants from all regions of the world and from as many countries as possible, especially countries of first asylum. It was amazing how challenging this proved to be. Even to begin, it was difficult to identify organizations to which we could send the conference information, especially when we wanted to identify NGOs that are working on the ground with refugees and displaced persons.

There is no organizational infrastructure to bridge these two realities, and even technological inequities serve as barriers. In following up from the conference focusing on building networks we are challenged with the reality that some participants do not have access to e-mail, the internet, or even a telephone.

Another part of our challenge is the language we speak and the imagery behind the language that works against developing common strategies. I recently attended an international meeting on detention. The participants brought different perspectives to the debate. Detention in countries like Canada and the US means confinement in institutional, jail-like settings. In many countries in Africa and Asia the reality of detention is the closed camp system containing many tens of thousands of people, sometimes for decades. This is no institutional prison setting but the high fences, armed guards, and national laws are just as effective. Nevertheless, when we talk about detention, NGOs don't often talk about camp-based containment as detention.

\section{Linkage between Human Rights Advocacy NGOs, Humanitarian Assistance, and Development NGOs}

Another illustration of a great divide is demonstrated every year during the UNHCR's Annual Consultation with NGOs, also known as the Pre ExCom. The participants, the agenda, and the discussions follow two very distinct tracks for the humanitarian aid organizations and the advocacy/rights based organizations. I was amazed at the degree of separation until I thought about our own Canadian experience and realized that we don't really talk to each other in Canada either.

The Humanitarian Assistance and Development NGOs uphold refugee rights in direct support, front-line services, and programs with tangible impact, often at the most basic level such as tents, clean water, food, and primary medical care. Advocacy NGOs seek protection and sustainment of human rights through political initiatives, international and national agreements and policies, donorship, and solution building. The two tracks are mutually supportive yet there seems to be very little dialogue between the two sectors to develop common strategies towards achieving shared goals.

\section{NGO Reliance on Independent Research and the Academic Sector}

We practitioners need researchers to support our voice. Oftentimes we are mired in the anecdotes of our day-to-day challenges and, while our instincts tell us there is a bigger picture that will demonstrate trends, systemic issues and potential strategies, we have neither the resources nor the skills to gather and analyze what we know.

Government-funded research is too often self-limited by the agendas of the funders who seek research data as a means to confirm policies rather than as a tool to provide guidance in policy development. The political agenda around migration issues, be they national or international, is a particularly hot topic that generates wide polarization of interests. For this reason independent research in the field of migration is essential. It provides the objective perspective to support human rights first and does not give license for the political and economic agendas to override the international community's commitments made in 1948.

\section{The Voice of the South in the North}

Refugees and other migrants always leave someone behind: family, friends, community. A part of the relationship that travels south to north is the trust to give voice to what is happening. This voice is often the most immediate and precedes media, international and national attention, and civil society response. Two examples: recently impoverished people have been forcibly displaced to build the new airport in Mexico City, and resisters have been arrested or have disappeared; second, in Oaxaca, civil demonstrations have resulted in executions and arrests. As of today, these two situations have barely been reported in the mainstream media, partly because the government has quashed freedom of the press; however, personal accounts and photographs distributed by e-mail and over the internet give voice and demand a response to human rights violations that would otherwise remain unheard.

Immigrants and refugees, especially those who flee early in a conflict or developing humanitarian crisis, shed light on situations that perhaps do not receive attention from our governments or from ordinary citizens. Sometimes the news is seen as not credible but over a period of time becomes more widely accepted. For example, asylum seekers arriving from Zimbabwe early in this decade of oppression suffered a high refusal rate in seeking protection in Canada. More recent Zimbabwean refugee claimants have benefited from the awareness of the international commu- 
nity that came later. In a second example, the Sierra Leone community in Canada advocated for special initiatives to provide protection through resettlement for their friends and relatives during a time when there was no Canadian response to the civil war in Sierra Leone. Public information and the pictures of that tragedy have come since the first voices were raised by Sierra Leone exiles.

\section{In Conclusion}

In conclusion, we can see that our opportunities to strengthen human rights lie very much in our willingness and ability to engage in dialogues with each other. Advocacy prompted by the voices of the oppressed and displaced, supported by valid research, and promoted across sectors and geography will build a powerful network. Your research and analysis is an essential component of that network and I invite you to continue to take a significant role and to work closely with NGOs. On behalf of the Canadian Council for Refugees I look forward to building on this conference and thank you again for the opportunity to speak to you today.

Elizabeth McWeeny is President of the Canadian Council for Refugees. She has been involved in the promotion of refugee rights for over twenty-five years and lives with her family in Thunder Bay, Ontario, Canada. 